Article

\title{
Preparation and Enhanced Photocatalytic Properties of 3D Nanoarchitectural ZnO Hollow Spheres with Porous Shells
}

\author{
Lan Li, Lijuan Han, Yuqi Han, Zhiwang Yang, Bitao Su * (iD) and Ziqiang Lei \\ Key Laboratory of Eco-Environment-Related Polymer Materials, Ministry of Education of China, \\ Key Laboratory of Polymer Materials of Gansu Province, College of Chemistry and Chemical Engineering, \\ Northwest Normal University, No. 967 Anning East Road, Lanzhou 730070, China; lilan316@163.com (L.L.); \\ ljhanzhang@163.com (L.H.); hexihxx@163.com (Y.H.); yjf75@163.com (Z.Y.); leizq@nwnu.edu.cn (Z.L.) \\ * Correspondence: subt0608@163.com; Tel.: +86-181-9419-8002
}

Received: 7 August 2018; Accepted: 30 August 2018; Published: 4 September 2018

\begin{abstract}
By using ginkgo leaves (GL) as template and $\mathrm{Zn}\left(\mathrm{CH}_{3} \mathrm{COO}\right)_{2} \cdot 2 \mathrm{H}_{2} \mathrm{O}$ as $\mathrm{Zn}$ source, a series of $\mathrm{ZnO}$ samples with special morphology were prepared via a template-assisted two-steps method without adding any other additives. The degradation of the dye MB was used to evaluate the photocatalytic property of the as-prepared samples. The results showed that when a proper amount of the template was used, a 3D nanoarchitectural $\mathrm{ZnO}$ hollow sphere with porous sphere shell assembled by well-distributed nanoparticles was obtained and its photocatalytic activity was much higher than that of $\mathrm{ZnO}$ nanoparticles. The special morphology of the sample was herein considered to be very helpful for highly efficient adsorption and activation of reactant molecules by multi-times adsorption-desorption-adsorption, efficient absorption of irradiation light by repeated absorption-reflection-absorption, and efficient separation of the photogenerated $e^{-}-h^{+}$ pairs. In addition, the formation of 3D structure of sample $\mathrm{ZnO}$ was also discussed.
\end{abstract}

Keywords: ZnO; Ginkgo leaves; hollow spheres with porous shells; template-assisted two-steps method; photocatalytic property

\section{Introduction}

In recent years, environmental pollution has become one of the major problems urgently needed to be solved by society. Among the many technologies used to control environmental pollution, photocatalysis has become the future star of environmental treatment technology due to its advantages of using sunlight, complete mineralization of pollutants without secondary pollution and simple equipment. Therefore, the development of green and environment-friendly photocatalysts with higher photocatalytic activity, high stability, high solar energy utilization rate and low cost has become a hot spot and difficulty in the study of photocatalysis [1-3].

$\mathrm{ZnO}$ is one of the most widely used photocatalysts for the decomposition of organic pollutants due to its quite excellent physical, chemical, and biological features, such as wide direct bandgap ( 3.37 $\mathrm{eV})$, hexagonal-wurtzite crystal structure, highly robust, extremely biofriendly, low cost, and high photocatalytic property, etc. [4-6]. The wide bandgap of $\mathrm{ZnO}$ is very advantageous because UV light gets easily absorbed and afterwards the blue as well as green light is emitted corresponding to exciton and defect recombinations which is extremely helpful for photocatalytic applications [7-9]. In order to improve its photocatalytic activity, a number of traditional strategies have been developed, such as doping metal and nonmetal elements [10,11], depositing noble metals [12,13], coupling inorganic-inorganic and inorganic/organic semiconductors [14,15], and modification with carbon materials $[16,17]$. In recent years, researchers have also realized that building 3D nanoarchitecture is an 
efficient method for improving the performance of $\mathrm{ZnO}$ semiconductor [18-21]. Compared with one dimensional (1D) or two dimensional (2D) nanostructures, a three dimensional (3D) architecture with highly specific surface area will likely have unique chemical and physical properties that differ from one dimensional (1D) or two dimensional (2D) nanostructures and that lead to the enhancement of photocatalytic performance [22-24]. For instance, the Nirmalya group [25] prepared porous $\mathrm{ZnO}$ spheres via one-step growth process at low temperature by using $\mathrm{Zn}\left(\mathrm{NO}_{3}\right)_{2}$ as $\mathrm{Zn}$ source and hexamethylenetetramine (HMTA) and ammonia solution as alkaline reagents and $\mathrm{C}_{6} \mathrm{H}_{5} \mathrm{Na}_{3} \mathrm{O}_{7}$ as structure-directing agent, which suppressed the growth of $\mathrm{Zn}(\mathrm{OH})_{2}$ crystal in all directions and thus resulted in spherical morphology of $\mathrm{ZnO}$. The as-prepared sample exhibited high photocatalytic activity for MO degradation under UV light irradiation. Yu et al. [26] obtained two kinds of 3D flower-like $\mathrm{ZnO}$ architectures (hydrangea and rose) by using hydrothermal method under sodium dodecyl sulfate (SDS) as surfactant and urea and HMTA as alkaline reagents. Both samples can photocatalytically degrade $\mathrm{RhB}$ for $25 \mathrm{~min}$ of UV irradiation. It can be seen that many assistant regents including precipitant, surfactants, stabilizer, slow-releasing regent and structure-directing agent and so on, are added during the related preparation processes, thus bringing about environmental pollution and higher cost.

In fact, it can be well-understood that a special morphology of photocatalyst is certainly important for improving its photocatalytic property [27]. A heterogeneous catalytic process including the absorption of irradiated light, the adsorption and activation of the reactant molecules, and further oxidization/reduction by photogenerated $h^{+} / e^{-}$, occurs on its surface/interface. So, developing a green and low-cost method is necessary for preparing $\mathrm{ZnO}$ photocatalyst with special morphology and good photocatalytic activity. Template method is one of the very efficient methods for constructing 3D multilevel nanoarchitecture of the target samples because the morphology, structure, arrangement, size, and partial functional groups of the templates can play the roles of spatial confinement and structure guiding under proper conditions. In recent years, great efforts have been devoted to utilizing biomass with special structure/morphology and functional groups as templates for preparing the goal materials with special morphology and improved the performance, such as eggshells [28], butterfly wings [29], and cotton fibers [30-33].

Ginkgo is one of the oldest trees and is mainly found in the United States, China and other Asian countries. A lot of ginkgo leaves is yearly abandoned, which cause waste of resource and the pollution of environment. Its leaves are nearly semicircular and contain many constituents, such as lactones, flavonoids, polyphenol, and acids. These constituents have many functional groups, including phenolic hydroxyl and carboxyl and ketone groups, and multiple ring structure [34]. Thus, using ginkgo leaves as template to prepare $\mathrm{ZnO}$ with special morphology is one of efficient paths, which can not only fully use the resource but also reduce the environmental pollution.

Our group has been interested in highly efficient photocatalysis in the long term [20,30-33,35]. In recent years, we have begun to prepare photocatalysts with multilevel nanoarchitectures and developed several template-related methods $[21,30-33,36]$. In this article, we report a green preparation and enhanced photocatalytic property of 3D nanoarchitectural $\mathrm{ZnO}$ hollow sphere with porous spherical shell via a template-assisted two-steps method by using ginkgo leaves as template. In addition, the morphology formation of the material and the approach of enhancing photocatalytic properties are also discussed.

\section{Materials and Methods}

\subsection{Materials}

Zinc acetate dihydrate $\left(\mathrm{Zn}\left(\mathrm{CH}_{3} \mathrm{COO}\right)_{2} \cdot 2 \mathrm{H}_{2} \mathrm{O}\right)$ was purchased from Shuangshuang Chemical Industry Co., Ltd., Laiyang, China.. Ethyl alcohol(EtOH) was supplied by Anhui Ante Biological Chemical Co., Ltd., Hefei, China. Methylene blue $\left(\mathrm{C}_{16} \mathrm{H}_{18} \mathrm{ClN}_{3} \mathrm{~S}, \mathrm{MB}\right)$ was bought from Tianjin Kaitong Chemical Reagent Co., Ltd. Tianjin, China. Tianjin Kaitong Chemical Reagent Co., Ltd. All of these 
reagents were analytically pure without further purification. Ginkgo leaves (GL) were collected from our campus in October.

\subsection{Preparation}

The pretreatment of ginkgo leaves: The collected ginkgo leaves were washed with distilled water, reflux extracted by Soxhlet extractor (Beijing Xinke Laboratory Glass Instrument Co. Ltd., Beijing, China) in the mixture of water and ethanol for $16 \mathrm{~h}$, and then dried naturally. The dried material was labeled as GL and stored for further use.

The $\mathrm{ZnO}$ samples were prepared by a novel template-assisted two-steps method, described as follows:

First step-solve-thermal process: $3.6000 \mathrm{~g} \mathrm{Zn}\left(\mathrm{CH}_{3} \mathrm{COO}\right)_{2} \cdot 2 \mathrm{H}_{2} \mathrm{O}$ was solved in $50.0 \mathrm{~mL} \mathrm{EtOH}$ and a certain amount of GL was added into the solution. Then the mixture was transferred into a $100 \mathrm{~mL}$ Telfon-linked autoclave, maintained at $200^{\circ} \mathrm{C}$ for $10 \mathrm{~h}$ and then naturally cooled to room temperature, the collected solid product was dried at $60^{\circ} \mathrm{C}$ for $3 \mathrm{~h}$ to obtain the precursor.

Second step-calcining process: The precursor was further calcined under air atmosphere and $650{ }^{\circ} \mathrm{C}$ for $1.5 \mathrm{~h}$ to fully remove the GL template and to obtain goal $\mathrm{ZnO}$ material. To investigate the function of the template GL for the formation of special morphology and the enhancement of photocatalytic property of $\mathrm{ZnO}$ materials, a series of $\mathrm{ZnO}$ samples were prepared by changing the added amount of GL $(0.0000,0.2500,0.8500,1.0000,1.5000 \mathrm{~g})$, and labeled as $\mathrm{ZnO}-0,-1,-2,-3$ and -4 , respectively.

\subsection{Characterization}

The morphology and microstructure of the samples were examined with a field emission scanning electron microscopy (FESEM; JEOL, JSM-6701F, Tokyo, Japan) and transmission electron microscopy (TEM; JEOL, JEM-2010, Tokyo, Japan). X-ray diffraction (XRD; D/Max-2400, Tokyo, Japan) with Cu $\mathrm{Kr}$ radiation $(\lambda=1.5418 \mathrm{~A})$ was used for phase identification. Photoluminescence (PL) spectra were measured at room temperature on a fluorescence spectrophotometer (PE, LS-55, Waltham, MA, USA) using a Xe lamp with an excitation wavelength of $325 \mathrm{~nm}$. UV-Vis spectra of the samples were analyzed by Hitachi u-2001 spectrophotometer (Tokyo, Japan) from $200 \mathrm{~nm}$ to $800 \mathrm{~nm}$. Brunauer-Emmett-Teller nitrogen adsorption-desorption experiments were carried out on the automated surface area and pore size analyzer (BET, TriStar II, Micromeritics Instrument, Atlanta, GA, USA). Solid state diffuse reflectance UV-vis spectrum was recorded at room temperature in air and spectrometer was equipped with an integrating sphere attachment; and $\mathrm{BaSO}_{4}$ was used as background reference materials (DRS, TU-1901, Beijing Purkinje General Instrument Co. LTD, Beijing, China).

\subsection{Photocatalytic Activity Measurements}

Photocatalytic experiments were carried out on a XPA-7 (G8) photocatalytic reactor equipped with $300 \mathrm{~W}$ high pressure Hg lamp (HPHL) as the UV irradiation source, which was built in the reactor and surrounded by a quartz circulating water quartz circulating water jacket to cool it, was used as the irradiation source. Catalytic reaction was carried out in a group of parallel quartz tubes. These tubes were placed to the lamp and the light distance was about $10 \mathrm{~cm}[20,30-33]$. Methylene blue (MB) was used as a probe molecule to evaluate the photocatalytic activity of samples. Prior to illumination, a suspension containing $40 \mathrm{mg}$ of the sample and $40 \mathrm{~mL}$ of $20 \mathrm{mg} \cdot \mathrm{L}^{-1} \mathrm{MB}$ was magnetically stirred in the dark for $30 \mathrm{~min}$ to attain adsorption-desorption equilibrium. The suspension was then illuminated, $5 \mathrm{~mL}$ of the suspension was sampled at regular intervals and centrifuged to remove the photocatalyst and the absorbance value of the supernatant was measured at $664 \mathrm{~nm}\left(\lambda_{\max }\right.$ of $\left.\mathrm{MB}\right)$. The decolorization efficiency and first-order kinetic equation of MB solution are $D_{t} \%=\left(A_{0}-A_{t}\right) / A_{0} \times 100 \%$ and $\ln \left(C_{0} / C_{\mathrm{t}}\right)=k_{1} t$, in which $A_{0}$ and $A_{t}, C_{0}$ and $C_{t}$ are the absorbance and concentration values of $\mathrm{MB}$ solution at the initial time $t=0$ and reaction time $t$, respectively, $k_{1}$ is the pseudo-first-order reaction rate constant $\left(\mathrm{min}^{-1}\right)$. 


\section{Results and Discussion}

\subsection{XRD Analysis}

The XRD patterns of the samples $\mathrm{ZnO}-0,-2$ and -4 are depicted in Figure 1 . It can be found that these samples are wurtzite $\mathrm{ZnO}$, well matching with JCPDS card no. 361451, but their diffraction intensities are different and the intensity order is $\mathrm{ZnO}-0>\mathrm{ZnO}-2>\mathrm{ZnO}-4$. And from Figure $1 \mathrm{~b}$, it can be also seen that their peaks successively occur shift to higher diffraction angle $(2 \theta)$, which means the decrease of $\mathrm{ZnO}$ crystal cell, and become broaden. The phenomena are related to many factors, such as the lattice defect, crystalline degree, and size of the samples. The particles size of the samples, calculated from Scherrer's equation, are 52, 30 and $28 \mathrm{~nm}$, respectively. So the as-obtained materials are nanosized and the template GL can efficiently control the size of the goal material. The crystalline property of the samples can be understood as follows. On the one hand, when the amount of the added GL is relatively low, the amount of the adsorbed- $\mathrm{Zn}^{2+}$ ions on its surface is high on the unit surface of the template and a large amount of $\mathrm{ZnO}$ nucleus is produced during the solvothermal process, which is benefit to the growth of the $\mathrm{ZnO}$ crystal. When the amount of the added GL is relatively high, the amount of the adsorbed- $\mathrm{Zn}^{2+}$ ions is low and thus the amount of $\mathrm{ZnO}$ nucleus is low, which is disadvantageous for the growth of the $\mathrm{ZnO}$ crystal. On the other hand, because the combustion of the template GL and the conversion of adsorbed $\mathrm{Zn}^{2+}$ ions to $\mathrm{ZnO}$ all need [O] during the calcining process in air atmosphere. The more the amount of used GL is, the more the needed [O] is. So, in the obtained $\mathrm{ZnO}$ samples with the presence of the template GL, the existence of oxygen vacancy might be expected and brings about the crystalline decrease of the samples.
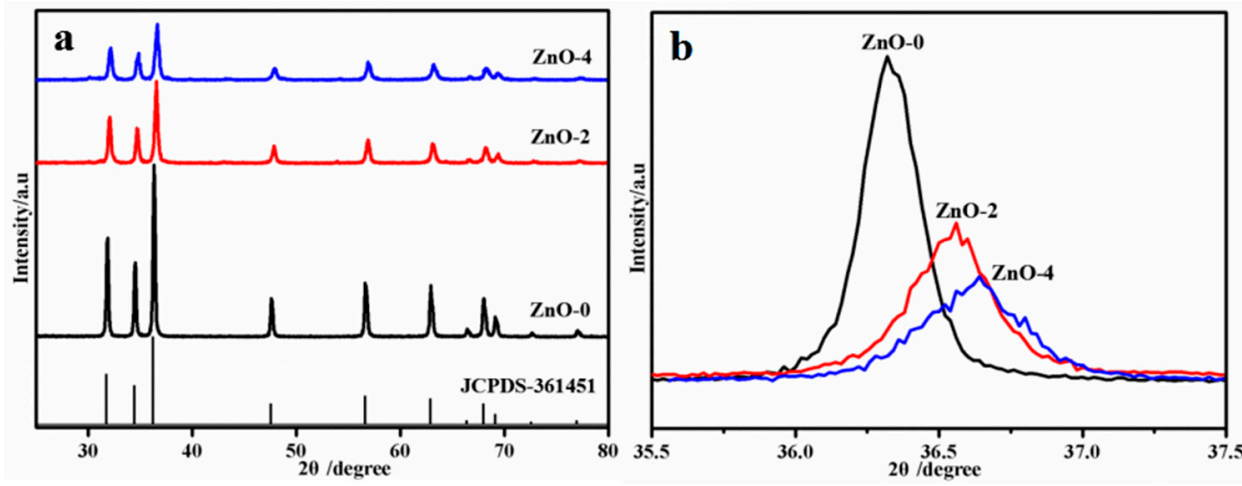

Figure 1. XRD patterns (a) and the local amplification (b) of the samples $\mathrm{ZnO}-0,-2$ and -4 .

\subsection{SEM Analysis}

FESEM images of the samples $\mathrm{ZnO}-0,-2$ and -4 are shown in Figure 2. ZnO-0 (Figure 2a), obtained without introducing GL, is a nanoparticle aggregate. ZnO-2 (Figure 2b), obtained by using a proper amount $(0.8500 \mathrm{~g})$ of GL, is basically hollow spheres, and the size of these spheres is different (the inset of Figure 2b). Herein the 3D nanoarchitectural $\mathrm{ZnO}$ hollow spheres are called multi-structured material because the shell of the hollow spheres is assembled by nanoparticles. Compared with $\mathrm{ZnO}-2$, $\mathrm{ZnO}-4$ (Figure 2c) shows irregular morphology, which results from the collapse of hollow sphere due to its thin sphere shell.

GL has many veins and mesophylls surrounded by veins and the size of the mesophylls is different and the closer the mesophyll is to the petiole, the smaller the mesophyll is (see in Scheme 1). So, it is easily understood that the size of the mesophylls controls the size of as-obtained ZnO hollow spheres and the smaller the mesophyll is and the smaller the size of as-obtained $\mathrm{ZnO}$ spheres is. And with increasing the amount of added GL (more than an optimal one), the sphere shell becomes thinner and thinner and will partially/fully collapse during the cooling process and thus the multi-structure is partially/fully destroyed. 

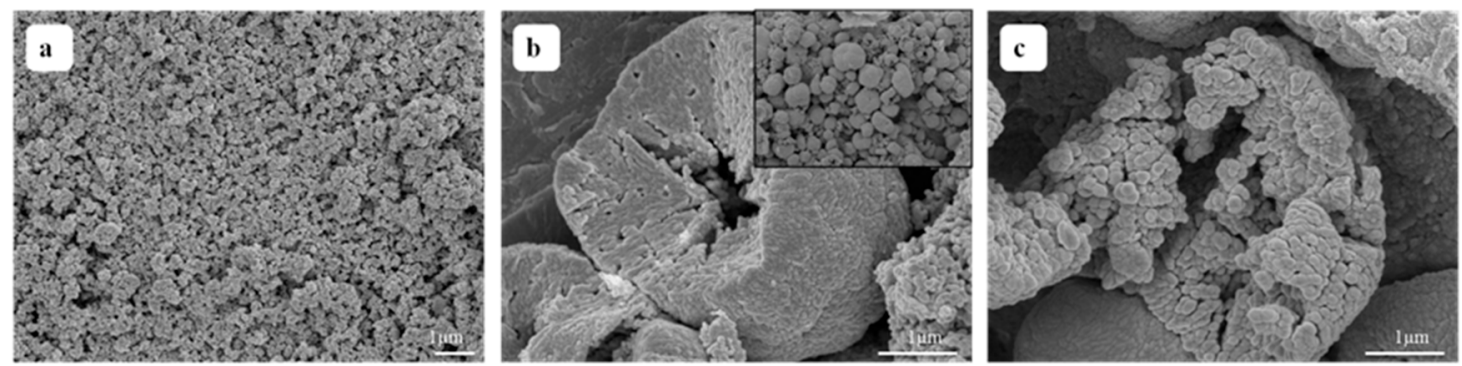

Figure 2. SEM images of the samples $\mathrm{ZnO}-0$ (a); -2 (b) and -4 (c).

\subsection{TEM Analysis}

The detailed structures of the samples $\mathrm{ZnO}-0, \mathrm{ZnO}-2$ and $\mathrm{ZnO}-4$ are observed by their TEM images. The sample $\mathrm{ZnO}-0$ is nanoparticles with wide size distribution (40-300 nm) and obvious aggregation is observed. The sample $\mathrm{ZnO}-2$, prepared by introducing an appropriate amount GL as template, is a structure of hollow sphere, its porous sphere shell is assembled by nanoparticles of almost mono-size (about $30 \mathrm{~nm}$ ) and regular hexagon (seen in the inset of Figure 3b). However, the sample $\mathrm{ZnO}-4$ is of heavily broken hemisphere (Figure 3c).

The SEM and TEM results of these samples are confirmed each other and demonstrate that a proper amount of GL can play a role of the template for efficiently controlling the morphology/microstructure and further improving the property of the goal material (seen in Section 3.4).
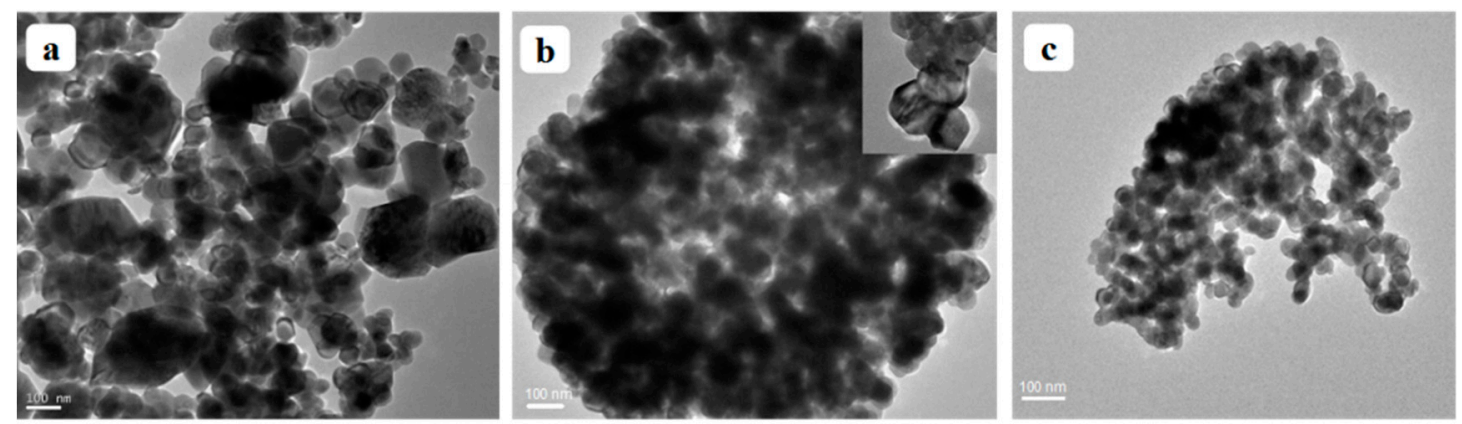

Figure 3. TEM images of the samples $\mathrm{ZnO}-0$ (a); -2 (b) and -4 (c).

On the formation of the 3D nanoarchitectural $\mathrm{ZnO}$ hollow spheres with porous shells, it can be described as follows: Two sides (up-down) structures of the ginkgo leaves are different. On the up-side, the arrangement of the cells is relatively order and dense. At the first step of preparation-the solvothermal process, $\mathrm{Zn}^{2+}$ ions are firstly adsorbed on the two sides of $\mathrm{GL}$, the amount of adsorbed $\mathrm{Zn}^{2+}$ ions is different on the two sides, and thus the amount and density of the in-situ formed $\mathrm{ZnO}$ nanoparticles is also different (seen in Scheme 1). At the second step (calcining process), the $\mathrm{ZnO} / \mathrm{GL}$ precursor is calcined under air atmosphere and a proper temperature to remove the template GL by its combustion and then cooled naturally. During the natural cooling, the curling phenomenon occurs because of different stress of the both sides and thus the multilevel structure is formed. It can be expected that when the amount of the GL is lower than a proper value, the as-obtained sample should be a certain number of hollow spheres with relative dense sphere shell while the sample is composed a large amount of badly broken hemispheres and nanoparticles when the amount of the GL is much higher than a proper value. So, adding a proper amount of GL can ensure the formation of the special morphology, hollow spheres with porous shells. 


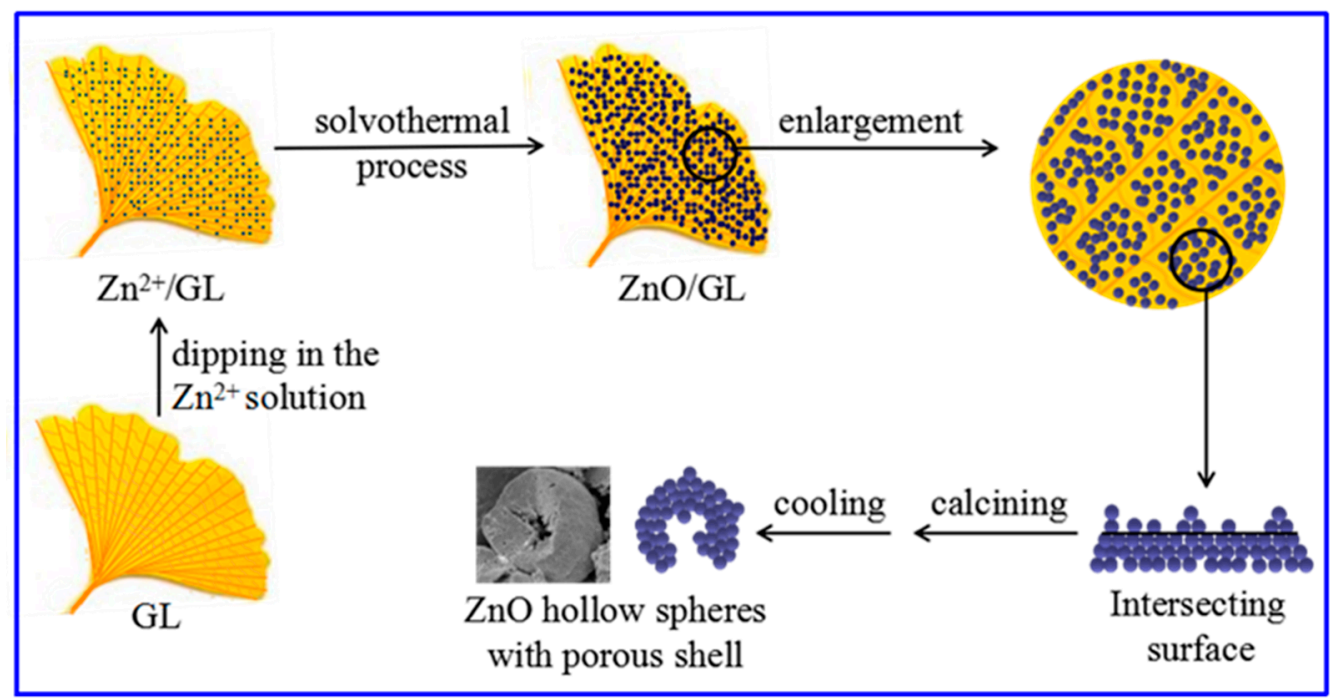

Scheme 1. The formation processes of 3D nanoarchitectural $\mathrm{ZnO}$ hollow spheres with porous shells.

\subsection{BET analysis}

Nitrogen adsorption/desorption measurements were used to test the Brunauer-Emmett-Teller (BET) surface areas of the as-prepared samples. The BET surface areas of samples were investigated by nitrogen adsorption-desorption experiments. As shown in Figure 4. All the samples exhibit typical type-III curves. The quantity adsorbed of $\mathrm{ZnO}$ prepared by GL showed higher than $\mathrm{ZnO}-0$. $3 \mathrm{D}$ nanoarchitectural $\mathrm{ZnO}$ hollow spheres having high specific surface area was obtained.

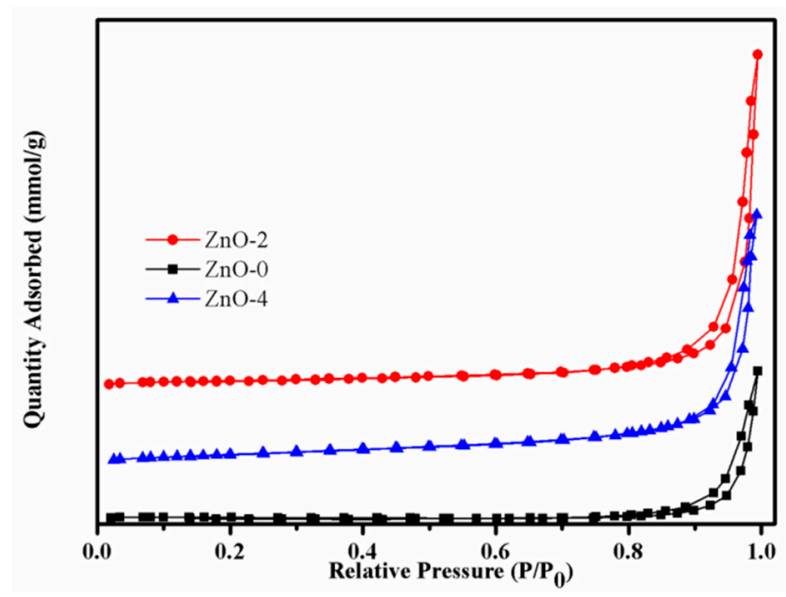

Figure 4. Nitrogen absorption-desorption isotherms of the samples $\mathrm{ZnO}-0,-2$ and -4 .

\subsection{DRS Analysis}

Figure 5 shows the UV-Vis DRS spectra of samples. The band gap energy ( $E g$ ) values of samples were calculated as approximately $3.20 \mathrm{eV}$ from the first derivative of the reflectance to a wavelength ( $D R / D \lambda, R$ is reflectance and $\lambda$ is wavelength), which were the lower than bulk ZnO NPs powder $(E g=3.37 \mathrm{eV})[4]$. This variation in band gap might be due to various factors such as structural parameter, carrier concentration, grain size, and induced defects. 


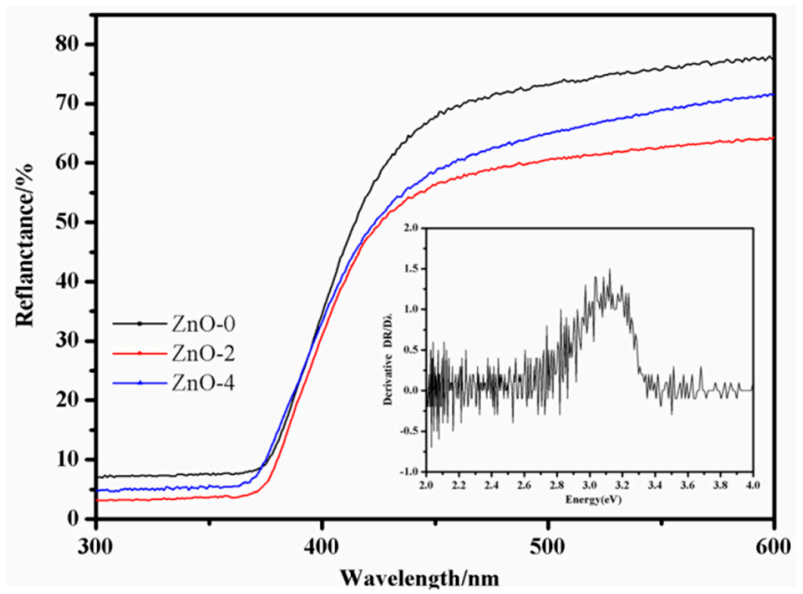

Figure 5. Diffuse reflectance measurement of the samples $\mathrm{ZnO}-0,-2$ and -4 , together with the first derivative of $\mathrm{ZnO}-2$ (inset) to describe the band gap.

\subsection{Photocatalytic Activity}

Based on the unique structural and morphological characteristic of $\mathrm{ZnO}$, the photocatalytic activity for $\mathrm{MB}$ degradation is tested. Figure 6a shows the degradation rate of $\mathrm{MB}$ on the samples $\mathrm{ZnO}-0 \sim 4$. And all the samples exhibit very high photocatalytic performance for the degradation of MB solution. Herein it is much meaningful that the activities of the samples $\mathrm{ZnO}-1 \sim 4$ prepared with the presence of GL are higher than $\mathrm{ZnO}-0$ which is prepared without the presence of GL. The photocatalytic activity firstly increases with increasing the amount of added GL and reaches an optimal activity when the amount is about $0.8500 \mathrm{~g}$ and then decreases with further increasing the GL amount. Figure $6 \mathrm{~b}$ gives the results of $\ln \left(C_{0} / C_{t}\right) \sim t$. It is obvious that the photocatalytic degradations of MB solution apparently for all samples follow first-order kinetic behavior $\ln \left(C_{0} / C_{\mathrm{t}}\right)=k_{1} t$. The reaction rate constant $k_{1}$ can be obtained from the Figure $6 \mathrm{~b}$. For example, the photocatalytic activity of $\mathrm{ZnO}-2\left(0.282 \mathrm{~min}^{-1}\right)$ is nearly 6 times as $\mathrm{ZnO}-0\left(0.049 \mathrm{~min}^{-1}\right)$. Figure $6 \mathrm{c}$ shows that the absorbance spectra of the $\mathrm{MB}$ solutions in the range 200-800 nm under regular interval of time in order to verify the mineralization ability of the sample $\mathrm{ZnO}-2$. It shows the decreasing trend of absorption for $\mathrm{ZnO}$ as photocatalyst. A strong absorption band at $664 \mathrm{~nm}$ represents maximum wavelength for MB dye. In dark conditions, the decrease of absorbance was equal to about $2 \%$. Due to adsorption of dye molecules, $\mathrm{ZnO}$ as photocatalyst plays a vital role for photo-degradation application. Decrease in absorbance intensity clearly confirms that $\mathrm{ZnO}$ are acting as photocatalyst for the degradation of dye. Complete degradation of dye was observed in 12 min under UV irradiation, the color of MB solution changes from dark blue to colorless.
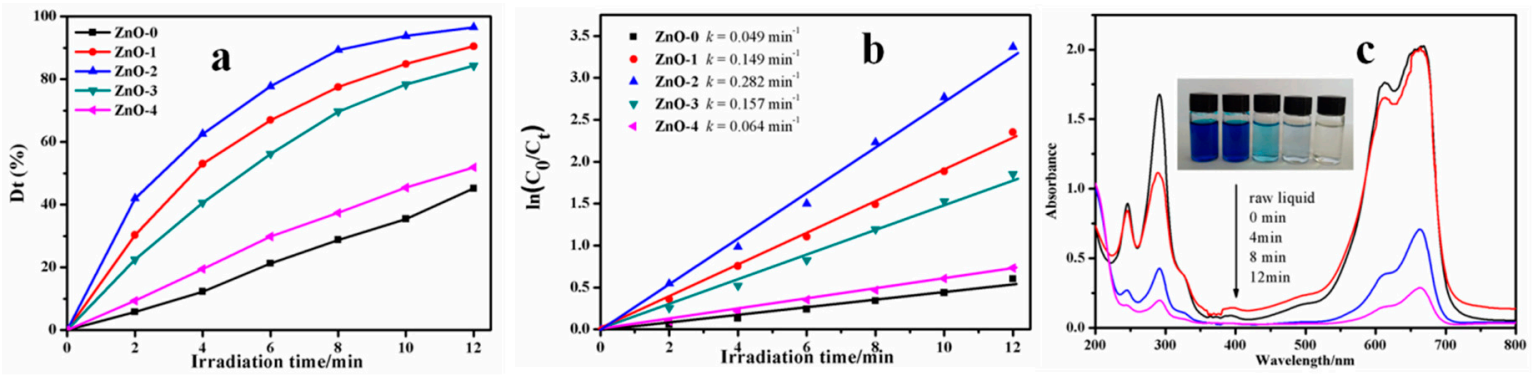

Figure 6. (a) $D_{\mathrm{t}} \sim t$ of the samples $\mathrm{ZnO}-0 \sim 4$; (b) The pseudo-first-order reaction rate constant of the samples $\mathrm{ZnO}-0 \sim 4$; (c) Absorbance spectra for photocatalytic degradation of MB on the sample $\mathrm{ZnO}-2$.

From XRD, SEM and TEM results of the samples, many factors, such as the size, crystalline degree, defect/oxygen vacancy, and morphology of the samples, are considered to affect the photocatalytic 
performance. In general, for a heterogeneous photocatalytic reaction, the smaller the size of the used catalyst is, the larger its surface area is, the more the active site is, and the higher its photocatalytic activity is. And it is well known that a proper crystallinity and some structural defect of a catalyst are also important for ensuring its good catalytic property.

For the highest activity of the sample $\mathrm{ZnO}-2$, the special morphology/microstructure is herein considered to be a more important factor (Figures 2 and 3). Why the 3D nanoarchitecture of a photocatalyst is so important to its good photocatalytic performance? We consider that on the enhanced photocatalytic performance of as-obtained $\mathrm{ZnO}$ hollow spheres with porous shells, the special nanoarchitecture structure of the material herein plays many roles of ensuring higher efficient adsorption of the reactant molecules by multi-times adsorbing-desorbing-re-adsorbing, higher efficient absorption of the irradiation light by repeatedly absorbing-reflecting-absorbing through the porous shell and inner cavity of the hollow sphere (seen in Figure 7a), and efficient separation of photogenerated $e^{-}-h^{+}$ pairs (seen in Figure $7 \mathrm{~b}$ ) for enhancing the photocatalytic performance. PL technique is a powerful tool to demonstrate the separation efficiency of photogenerated charges. The lower the PL intensity of a photocatalyst, the lower the recombination of $e^{-}-h^{+}$pairs is, the higher its photocatalytic activity is [32]. Figure 7c illustrates the PL spectra of the samples $\mathrm{ZnO}-0$ and $\mathrm{ZnO}-2$ with an excitation wavelength of $325 \mathrm{~nm}$. It can be seen that there are several weak emission peaks for the sample $\mathrm{ZnO}-0$. These origin broad unstructured emissions bands in $\mathrm{ZnO}$ cover the blue, green, yellow, orange, and red spectral zones, and they are frequently assigned to native defects such as oxygen vacancies $\left(V_{\mathrm{O}}\right)$, zinc vacancies $\left(V_{\mathrm{Zn}}\right)$, oxygen interstitials $\left(O_{\mathrm{i}}\right)$, zinc interstitials $\left(Z n_{\mathrm{i}}\right)$, and their complexes. In general, the strong PL means high recombination of photogenerated carriers, suggesting the low photocatalytic activity [37-39]. The PL intensity of the sample ZnO-2 is remarkably weaker than that of $\mathrm{ZnO}-0$, which indicates fast separation of photogenerated $e^{-} / h^{+}$pairs in $\mathrm{ZnO}-2$. The efficient interparticle transfer of the photogenerated charges through the grain boundaries has been suggested and demonstrated $[40,41]$. In this paper, we suggest a more efficient separation path of the $e^{-} / h^{+}$ pairs in the described-above special morphology of $\mathrm{ZnO}$ photocatalyst by comparing the activities and morphologies of the sample $\mathrm{ZnO}-2$ and $\mathrm{ZnO}-0$ and $\mathrm{ZnO}-4$ (seen in Figure 3). We suggest that the potential energy $\left(\mu_{\mathrm{e}}\right)$ of the photogenerated $\mathrm{e}^{-}$should be different on the irradiated and no irradiated $\mathrm{ZnO}$ particles and $\mu_{\mathrm{e}}$ is higher on the irradiated $\mathrm{ZnO}$ particles than on no irradiated ones. So, the migration of these photogenerated electrons is easier (seen in Figure $7 \mathrm{~b}(\mathrm{I})$ ) from the irradiated $\mathrm{ZnO}$ particles to no irradiated ones than among the irradiated $\mathrm{ZnO}$ particles (seen in Figure $7 \mathrm{~b}(\mathrm{II})$ ). Therefore, it brings about fast separation of the photogenerated $e^{-} / h^{+}$pairs and increases the stability of photogenerated holes $\mathrm{h}^{+}$and thus further increases the photocatalytic activity of the special 3D sample.
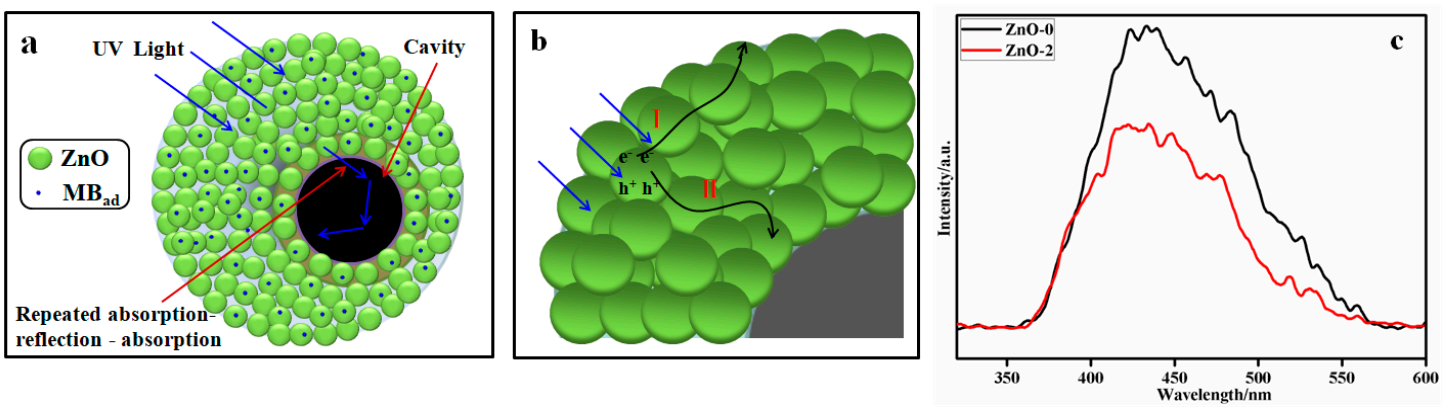

Figure 7. (a) Schematic drawing of highly efficient adsorption of the reactant molecules and high efficient absorption of irradiation light in the $\mathrm{ZnO}$ hollow sphere with porous sphere shell; (b) Schematic illustration for the migration process of the photogenerated electron in the sphere shell; (c) The photoluminescence spectra (PL) of the samples $\mathrm{ZnO}-0$ and $\mathrm{ZnO}-2$. 


\section{Conclusions}

A 3D nanoarchitectural $\mathrm{ZnO}$ sample, hollow spheres with porous shellss, was successfully prepared via template-assisted two-steps method by adding a proper amount of the GL template without adding any other additives. The special structure of the GL template and preparing method play an important role in the formation of the sample with special morphology. 3D nanoarchitectural $\mathrm{ZnO}$ hollow spheres with porous shells show excellent photocatalytic property for the degradation of MB molecules and its excellent photocatalytic property is considered to be mainly ascribed to highly efficient adsorption of reactant molecules by multi-times adsorption-desorption-adsorption and absorption for the reached light by repeated absorption-reflection-absorption through its porous shells and inner cavity and separation of the photogenerated $e^{-}-h^{+}$pairs by the migration of photogenerated electrons by interparticle transfer, especially from the irradiated $\mathrm{ZnO}$ particles to no irradiated ones in the special morphology of hollow spheres with porous shellssll.

Author Contributions: Data curation, L.L.; Formal analysis, L.L., L.H, and Y.H.; Investigation, L.L., L.H, Y.H., and Z.Y.; Resources, B.S.; Writing: Original Draft Preparation, L.L. and B.S.; Project Administration, B.S. and Z.L. All the authors discussed the results and commented on the manuscript.

Funding: This research was funded by Program for Changjiang Scholars and Innovative Research Team in University of Ministry of Education of China grant number (No. IRT1177) and the APC was funded by Scientific and Technical Innovation Project of Northwest Normal University (No. nwnu-kjcxgc-03-63).

Acknowledgments: This work was financially supported by Scientific and Technical Plan Project of Gansu province (No. 1204GKCA006), National Natural Science Foundation of China (No. 21174114) and National Natural Science Foundation of China (No. 21363021).

Conflicts of Interest: The authors declare no conflict of interest.

\section{References}

1. Chen, X.; Wu, Z.; Liu, D.; Gao, Z. Preparation of ZnO photocatalyst for the efficient and rapid photocatalytic degradation of azo dyes. Nanoscale Res. Lett. 2017, 12, 143. [CrossRef] [PubMed]

2. Vaiano, V.; Iervolino, G. Facile method to immobilize $\mathrm{ZnO}$ particles on glass spheres for the photocatalytic treatment of tannery wastewater. J. Colloid Interface Sci. 2018, 51, 192-199. [CrossRef] [PubMed]

3. Ong, C.B.; Ng, L.Y.; Mohammad, A.W. A review of ZnO nanoparticles as solar photocatalysts: Synthesis, mechanisms and applications. Renew. Sust. Energ. Rev. 2018, 81, 536-551. [CrossRef]

4. Wang, M.; Ren, F.; Zhou, J.G.; Cai, G.X.; Li, C.; Hu, Y.F.; Wang, D.N.; Liu, Y.C.; Guo, L.J.; Shen, S.H. $\mathrm{N}$ doping to $\mathrm{ZnO}$ nanorods for photoelectrochemical water splitting under visible light: engineered impurity distribution and terraced band structure. Sci. Rep. 2015, 5, 12925. [CrossRef] [PubMed]

5. Taheri, M.; Abdizadeh, H.; Golobostanfard, M.R. Formation of urchin-like ZnO nanostructures by sol-gel electrophoretic deposition for photocatalytic application. J. Alloys Compd. 2017, 725, 291-301. [CrossRef]

6. Wang, C.; Wang, L.; Jin, J.; Liu, J.; Li, Y.; Wu, M.; Chen, L.H.; Wang, B.J.; Yang, X.Y.; Su, B.L. Probing effective photocorrosion inhibition and highly improved photocatalytic hydrogen production on monodisperse PANI@CdS core-shell nanospheres. Appl. Catal. B Environ. 2016, 188, 351-359. [CrossRef]

7. Liang, X.Y.; Yang, X.Z.; Gao, G.J.; Li, C.F.; Li, Y.Y.; Zhang, W.D.; Chen, X.T.; Zhang, Y.B.; Zhang, B.B.; Lei, Y.Q.; et al. Performance and mechanism of $\mathrm{CuO} / \mathrm{CuZnAl}$ hydrotalcites-ZnO for photocatalytic selective oxidation of gaseous methanol to methyl formate at ambient temperature. J. Catal. 2016, 339, 68-76. [CrossRef]

8. Song, X.L.; Liu, Y.M.; Zheng, Y.; Ding, K.; Nie, S.J.; Yang, P. Synthesis of butterfly-like ZnO nanostructures and study of their self-reducing ability toward $\mathrm{Au}^{3+}$ ions for enhanced photocatalytic efficiency. Phys. Chem. Chem. Phys. 2016, 18, 4577-4584. [CrossRef] [PubMed]

9. Wang, J.; Xia, Y.; Dong, Y.; Chen, R.S.; Xiang, L.; Komarneni, S. Defect-rich ZnO nanosheets of high surface area as an efficient visible-light photocatalyst. Appl. Catal. B Environ. 2016, 192, 8-16. [CrossRef]

10. Pascariu, P.; Tudose, I.V.; Suchea, M.; Koudoumas, E.; Fifere, N.; Airinei, A. Preparation and characterization of Ni, Co doped ZnO nanoparticles for photocatalytic applications. Appl. Surf. Sci. 2018, 448, 481-488. [CrossRef]

11. Yu, W.L.; Zhang, J.F.; Peng, T.Y. New insight into the enhanced photocatalytic activity of N-, C- and S-doped ZnO photocatalysts. Appl. Catal. B Environ. 2016, 181, 220-227. [CrossRef] 
12. Wu, S.; Chen, Z.W.; Wang, T.; Ji, X.H. A facile approach for the fabrication of Au/ZnO-hollow-spheremonolayer thin films and their photocatalytic properties. Appl. Surf. Sci. 2017, 412, 69-76. [CrossRef]

13. Vaiano, V.; Matarangolo, M.; Murcia, J.J.; Rojas, H.; Navío, J.A.; Hidalgo, M.C. Enhanced photocatalytic removal of phenol from aqueous solutions using $\mathrm{ZnO}$ modified with Ag. Appl. Catal. B Environ. 2018, 225, 197-206. [CrossRef]

14. Faisal, M.; Ibrahim, A.A.; Harraz, F.A.; Bouzid, H.; Al-Assiri, M.S.; Ismail, A.A. SnO 2 doped ZnO nanostructures for highly efficient photocatalyst. J. Mol. Catal. A Chem. 2015, 397, 19-25. [CrossRef]

15. Eskizeybek, V.; Sarı, F.; Gülce, H.D.; Gülce, A.; Avc1, A. Preparation of the new polyaniline/ZnO nanocomposite and its photocatalytic activity for degradation of methylene blue and malachite green dyes under UV and natural sun lights irradiations. Appl. Catal. B Environ. 2012, 119-120, 197-206. [CrossRef]

16. Chen, T.T.; Chang, I.C.; Yang, M.H.; Chiu, H.T.; Lee, C.Y. The exceptional photo-catalytic activity of $\mathrm{ZnO} / \mathrm{RGO}$ composite via metal and oxygen vacancies. Appl. Catal. B Environ. 2013, 142-143, 442-449. [CrossRef]

17. Wang, H.; Qiu, X.Q.; Liu, W.F.; Yang, D.J. Facile preparation of well-combined lignin-based carbon/ZnO hybrid composite with excellent photocatalytic activity. Appl. Surf. Sci. 2017, 426, 206-216. [CrossRef]

18. Lukas, S.; Judith, L.M. ZnO-nanostructures, defects, and devices. Mater. Today 2007, 10, 40-48. [CrossRef]

19. Guo, Y.X.; Lin, S.W.; Li, X.; Liu, Y.P. Amino acids assisted hydrothermal synthesis of hierarchically structured $\mathrm{ZnO}$ with enhanced photocatalytic activities. Appl. Surf. Sci. 2016, 384, 83-91. [CrossRef]

20. Su, B.T.; Dong, Y.Y.; Jin, Z.J.; Wang, Q.Z.; Lei, Z.Q. Enhanced photocatalytic performance of ZnO/rGO composite materials prepared via an improved two-steps method. Ceram. Int. 2016, 42, 7632-7638. [CrossRef]

21. Dong, N.; He, F.Z.; Xin, J.L.; Wang, Q.Z.; Lei, Z.Q.; Su, B.T. A novel one-step hydrothermal method to prepare $\mathrm{CoFe}_{2} \mathrm{O}_{4}$ /graphene-like carbons magnetic separable adsorbent. Mater. Res. Bull. 2016, 80, 186-190. [CrossRef]

22. Gröttrup, J.; Schütt, F.; Smazna, D.; Lupan, O.; Adelung, R.; Mishra, Y.K. Porous ceramics based on hybrid inorganic tetrapodal networks for efficient photocatalysis and water purification. Ceram. Int. 2017, 43, 14915-14922. [CrossRef]

23. Gröttrup, J.; Paulowicz, I.; Schuchardt, A.; Kaidas, V.; Kaps, S.; Lupan, O.; Adelung, R.; Mishra, Y.K. Three-dimensional flexible ceramics based on interconnected network of highly porous pureand metal alloyed ZnO tetrapods. Ceram. Int. 2016, 42, 8664-8676. [CrossRef]

24. Xie, X.; Wang, X.; Tian, J.; Liu, J.; Cao, H.; Song, X.; Wei, N.; Cui, H. Facile synthesis and superior ethyl acetate sensing performance of Au decorated $\mathrm{ZnO}$ flower-like architectures. Ceram. Int. 2017, 43, 5053-5060. [CrossRef]

25. Tripathy, N.; Ahmad, R.; Kuk, H.; Lee, D.H.; Hahn, Y.B.; Khang, G. Rapid methyl orange degradation using porous ZnO spheres photocatalyst. J. Photochem. Photobiol. B 2016, 161, 312-317. [CrossRef] [PubMed]

26. Miao, Y.; Zhang, H.J.; Yuan, S.; Jiao, Z.; Zhu, X.D. Preparation of flower-like ZnO architectures assembled with nanosheets for enhanced photocatalytic activity. J. Colloid Interface Sci. 2016, 462, 9-18. [CrossRef] [PubMed]

27. Lu, J.; Wang, H.H.; Peng, D.L.; Chen, T.; Dong, S.J.; Chang, Y. Synthesis and properties of Au/ZnO nanorods as a plasmonic photocatalyst. Physica E 2016, 78, 41-48. [CrossRef]

28. Camaratta, R.; Messana, J.O.; Bergmann, C.P. Synthesis of ZnO through biomimetization of eggshell membranes using different precursors and its characterization. Ceram. Int. 2015, 41, 14826-14833. [CrossRef]

29. Huang, J.Y.; Wang, X.D.; Wang, Z.L. Controlled replication of butterfly wings for achieving tunable photonic properties. Nano Lett. 2006, 6, 2325-2331. [CrossRef] [PubMed]

30. Su, B.T.; Xin, J.L.; Li, J.J.; Dong, N.; Shao, K.R.; Wang, Q.Z.; Lei, Z.Q. Comparing the photocatalytic property of $\mathrm{TiO}_{2}$ nanoparticles and structured nanofiber materials. Micro Nano Lett. 2016, 11, 323-325. [CrossRef]

31. Su, B.T.; Xin, J.L.; Li, J.J.; Zheng, T.; Wang, Q.Z.; Lei, Z.Q. The role of multi-level structure for the improved photocatalytic performance of $\mathrm{TiO}_{2}$ fiber nanomaterials. Appl. Phys. A Mater. 2016, 122, 32. [CrossRef]

32. Zheng, T.; Tian, Z.; Su, B.T.; Lei, Z.Q. Facile method to prepare $\mathrm{TiO}_{2}$ hollow fiber materials via replication of cotton fiber. Ind. Eng. Chem. Res. 2012, 51, 1391-1395. [CrossRef]

33. Su, B.T.; Wang, K.; Dong, N.; Mu, H.M.; Lei, Z.Q.; Tong, Y.C.; Bai, J. Biomorphic synthesis of long ZnO hollow fibers with porous walls. J. Mater. Process. Technol. 2009, 209, 4088-4092. [CrossRef]

34. Ren, Y.Y.; Yang, H.; Wang, T.; Wang, C. Green synthesis and antimicrobial activity of monodisperse silver nanoparticles synthesized using Ginkgo Biloba leaf extract. Phys. Lett. A 2016, 380, 3773-3777. [CrossRef] 
35. Yang, Z.W.; Xu, X.Q.; Liang, X.X.; Lei, C.; Cui, Y.H.; Wu, W.H.; Yang, Y.X.; Zhang, Z.; Lei, Z.Q. Construction of heterostructured MIL-125/Ag/g- $\mathrm{C}_{3} \mathrm{~N}_{4}$ nanocomposite as an efficient bifunctional visible light photocatalyst for the organic oxidation and reduction reactions. Appl. Catal. B Environ. 2017, 205, 42-54. [CrossRef]

36. Jin, Z.J.; Dong, Y.Y.; Dong, N.; Yang, Z.W.; Wang, Q.Z.; Lei, Z.Q.; Su, B.T. One-step synthesis of magnetic nanocomposite $\mathrm{Fe}_{3} \mathrm{O}_{4} / \mathrm{C}$ based on the waste chicken feathers by a green solvothermal method. Mater. Lett. 2017, 186, 322-325. [CrossRef]

37. Lupan, O.; Postica, V.; Gröttrup, J.; Mishra, A.K.; de Leeuw, N.H.; Carreira, J.F.C.; Rodrigues, J.; Ben Sedrine, N.; Correia, M.R.; Monteiro, T.; et al. Hybridization of zinc oxide tetrapods for selective gas sensing applications. ACS Appl. Mater. Interfaces 2017, 9, 4084-4099. [CrossRef] [PubMed]

38. Chen, D.; Wang, Z.; Ren, T.; Ding, H.; Yao, W.; Zong, R.; Zhu, Y. Influence of Defects on the Photocatalytic Activity of ZnO. J. Phys. Chem. C 2014, 118, 15300-15307. [CrossRef]

39. Mishra, Y.K.; Adelung, R. ZnO tetrapod materials for functional applications. Mater. Today. 2018, 21, 631-651. [CrossRef]

40. Choi, S.K.; Kim, S.; Lim, S.K.; Park, H. Photocatalytic comparison of $\mathrm{TiO}_{2}$ nanoparticles and electrospun $\mathrm{TiO}_{2}$ nanofibers: Effects of mesoporosity and interparticle charge transfer. J. Phys. Chem. C. 2010, 114, 16475-16480. [CrossRef]

41. Zhou, Y.; Shuai, L.; Jiang, X.Y.; Jiao, F.; Yu, J. Visible-light-driven photocatalytic properties of layered double hydroxide supported- $\mathrm{Bi}_{2} \mathrm{O}_{3}$ modified by $\mathrm{Pd}(\mathrm{II})$ for methylene blue. Adv. Powder Technol. 2015, 26, 439-447. [CrossRef]

(C) 2018 by the authors. Licensee MDPI, Basel, Switzerland. This article is an open access article distributed under the terms and conditions of the Creative Commons Attribution (CC BY) license (http:/ / creativecommons.org/licenses/by/4.0/). 